\title{
Pobreza e desigualdade na distribuição de renda no Paraná: uma análise para o período $1995-2015^{*}$
}

\author{
Poverty and inequality in the distribution of income in Paraná: \\ an analysis for the period 1995-2015
}

\author{
Marina Silva da Cunha, Marcos Roberto Vasconcelos e Marcos Aurélio \\ Brambilla**
}

\begin{abstract}
Resumo: Neste trabalho é analisada a evolução da desigualdade na distribuição da renda e da pobreza no estado do Paraná entre 1995 e 2015. São utilizadas as informações da Pesquisa Nacional por Amostra de Domicílios do Instituto Brasileiro de Geografia e Estatística (PNAD/IBGE) e indicadores de desigualdade e pobreza. Os resultados expostos sugerem redução da desigualdade e da pobreza, notadamente na primeira década do século XXI, mas também que a crise econômica do final do período analisado parece ter iniciada a reversão nessa tendência. Embora com importância decrescente, a desigualdade educacional permanece como determinante mais significativo para explicar os diferenciais de renda. A pobreza relativa se ampliou entre os domicílios chefiados por mulheres e não brancos, e naqueles localizados na Região Metropolitana de Curitiba e em áreas urbanas. Apesar da melhoria dos indicadores de distribuição de renda, o Paraná ainda se constitui em uma sociedade extremamente desigual, demandando a ampliação de políticas públicas destinadas a mitigar essa adversidade.
\end{abstract}

Palavras-chave: Desigualdade. Renda. Pobreza. Crise econômica. Paraná

\begin{abstract}
This paper aims to discuss the evolution of inequality in income distribution and poverty in the state of Paraná, from 1995 to 2015. The National Household Sample Survey of the Brazilian Institute of Geography and Statistics (PNAD/IBGE) and indicators of inequality and poverty are used. The results of the study suggest a reduction of inequality and poverty, especially in the first decade of the 21 st century, and that, in general, the economic and political crisis of the end of the period caused a reversion in
\end{abstract}

\footnotetext{
* Submissão: 06/08/2019. Aprovação: 27/03/2020. DOI: http://dx.doi.org/10.5380/re.v41i76.68376. Este artigo faz parte do projeto de pesquisa "Desenvolvimento econômico e regional paranaense" que está no convênio 2/2017 entre a Universidade Estadual de Maringá e a Fundação Araucária. Os autores agradecem à Fundação Araucária pelo financiamento e aos pareceristas da Revista de Economia pelos valiosos comentários e sugestões.

** Respectivamente: (1) Professora titular do Departamento de Economia da UEM e bolsista produtividade em pesquisa do CNPq. E-mail: mscunha@uem.br. ORCID: 0000-0001-9122-3944. (2) Professor associado do Departamento de Economia da UEM. E-mail: mrvasconcelos@uem.br. ORCID: 0000-0003-1476-4899. (3) Professor do Instituto Adventista Paranaense (IAP). E-mail: marcos-brambilla@ hotmail.com. ORCID: 0000-0002-1111-9424.
} 
this trend. Although of decreasing importance educational inequality remains the most significant cause to explain income differentials. In addition, poverty has increased between the households headed by women and non-white, and those located in the Metropolitan Region of Curitiba and in urban areas. Despite, the improvement in income distribution indicators, Paraná is still an extremely unequal society, demanding the expansion of public policies aimed at mitigating these inequalities.

Keywords: Inequality. Income. Poverty. Economic crisis. Paraná

JEL Code: D30; I32; O15 


\section{Introdução}

Um reconhecido problema do processo de formação social e econômica brasileiro é a sua elevada desigualdade na distribuição da renda e da riqueza. A historiografia nacional encontra na produção agrícola baseada em grandes latifúndios, no longo e acentuado uso de trabalho escravo nas atividades econômicas - sendo marcante o fato de o Brasil ter sido o último país do ocidente a abolir a escravidão - e no modelo de industrialização estimulado pelo processo de substituição de importações, por exemplo, fatores socioeconômicos que contribuíram para essa característica do país (LOVELL, 1999; FURTADO, 1989; BAER, 2009; GREMAUD et al., 2012). Diante desse quadro, o Brasil chegou ao século XXI apresentando uma das mais altas desigualdades na distribuição de renda do mundo, em especial se compararmos o seu grau de desenvolvimento e complexidade econômica ante países similares. O índice de Gini médio dos países da OCDE, em 2014, era de apenas 0,318, enquanto, no Brasil, alcançava 0,513, segundo estimativas de Hoffmann (2016).

Porém um conjunto de ações do Estado, na primeira década deste século, foi voltado para atender as parcelas dos mais pobres da população e acabou contribuindo também para reduzir os níveis de desigualdade na distribuição da renda. Fizeram parte desse conjunto programas como o Bolsa Família e os aumentos reais no salário-mínimo. Ademais, os ganhos nos termos de troca, observados nos principais produtos de exportação brasileiros, associados a políticas de estímulo ao crédito auxiliaram para que o país apresentasse um ritmo de crescimento econômico expressivo entre 2005 e 2010, proporcionando aquecimento do mercado de trabalho e ganhos de renda. Assim, no decênio inaugural do novo século, o Brasil presenciou melhora nos seus indicadores de distribuição de renda, com as quedas nos índices de desigualdade acompanhados de aumento da renda funcional do trabalho (BASTOS, 2012; GOMES et al., 2019).

A partir do início da segunda década do século XXI, a reversão do cenário internacional favorável e a adoção de políticas econômicas equivocadas parecem ter prejudicado o desempenho da economia brasileira. A partir de 2011, as taxas de expansão do PIB sofrem desaceleração e passam, ao final de 2014, a apresentar flutuações negativas. Em conjunto, ocorreram o desaquecimento do mercado de trabalho e a consequente elevação dos níveis de desemprego (GOMES et al., 2019). 
De acordo com Hoffmann (2017), a redução da desigualdade na distribuição de renda no país foi significativa de 1995 até 2014, contribuindo para o arrefecimento da pobreza. Nesse período, o Brasil acompanhou o comportamento de queda na desigualdade da distribuição de renda observado na maioria dos países da América Latina, conforme destaca Atkinson (2015). Porém, de 2014 para 2015, Hoffmann (2016) nota estabilidade na desigualdade da distribuição da renda domiciliar per capita no país, com o índice de Gini igual a 0,513 nos dois anos, indicando interrupção do processo de retração da desigualdade. Portanto, se o país estava em uma tendência de diminuição da desigualdade na distribuição da renda, as crises econômicas e política observadas a partir de 2014 parecem ter impactado negativamente tal processo.

Nesse contexto, o objetivo neste trabalho é apresentar e discutir a trajetória da pobreza e da desigualdade na distribuição de renda em um dos estados brasileiros com os melhores indicadores de distribuição de renda e de pobreza: o estado do Paraná para o período de 1995 a 2015. Embora, ao longo dos anos 2000, tenham sido publicados diversos estudos direcionados a analisar tais questões, como exposto na próxima seção, nenhum deles abrangeu um período temporal tão extenso quanto o aqui tratado nem analisou conjuntamente diversos indicadores de distribuição de renda e de pobreza. Ademais, nos trabalhos referenciados sobre a pobreza, não foram analisados conjuntamente os indicadores de pobreza "proporção de pobres", "insuficiência de renda" e "severidade de pobreza" para o Paraná.

Em geral, as pesquisas relacionadas à temática distribuição de renda e pobreza indicam a melhor situação relativa do estado paranaense na comparação com o Brasil e outros estados nesses temas ${ }^{1}$. No entanto, como apontado na seção 4, quando se cotejam os dados relativos à desigualdade do Paraná com os observados em países desenvolvidos, ou mesmo de renda média, evidencia-se a condição do estado como ainda apresentando elevada concentração de renda, segundo padrões internacionais. Desse modo, é relevante indicar que, mesmo em um estado brasileiro comparativamente rico como o Paraná, permanece a necessidade de se desenvolverem estudos e ações capazes de colaborarem para a diminuição da pobreza e da desigualdade de renda.

\footnotetext{
${ }^{1}$ Conforme estudo apresentado por Barros et al. (1997), desde a década de 1970, o Paraná se mostra, juntamente com São Paulo, Rio Grande do Sul e Santa Catarina, um dos estados brasileiros com os melhores indicadores referentes à distribuição de renda e à pobreza.
} 
Assim, a partir do uso das informações da Pesquisa Nacional por Amostra de Domicílios anualmente levantados pelo IBGE de 1995 até 2015, além de avaliar um período extenso e recente de tempo, abrangendo diferentes fases dos ciclos econômicos da economia brasileira, neste trabalho é apresentado amplo leque de indicadores de desigualdade na distribuição de renda e de pobreza domiciliares para todos os anos contemplados na amostra, com destaque para o cálculo das três diferentes medidas tradicionais de pobreza: proporção de pobres (e extremamente pobres), índice de insuficiência de renda e índice de severidade. Também se expõem e se discutem várias características dos chefes de domicílios e da localização destes que podem estar influenciando tanto os aspectos atinentes à distribuição da renda quanto os relacionados à pobreza de tais unidades domiciliares.

Além desta introdução e das considerações finais, o presente artigo está organizado em mais cinco seções. Na seção 2, expõe-se sumária discussão dos trabalhos existentes sobre a temática aqui abordada. Na seção seguinte, são apresentados a fonte de dados e os indicadores utilizados para mensurar tanto a desigualdade quanto a pobreza no Paraná. Na seção 4, são expostos e discutidos vários indicadores de desigualdade na distribuição da renda domiciliar para o Paraná. Na seção seguinte, a partir do índice de Theil, procura-se identificar a contribuição de alguns dos principais determinantes da desigualdade da distribuição de renda. Na seção 6, o foco é a discussão sobre o perfil da pobreza no estado e a análise da sua evolução no período de 1995 até 2015.

\section{Estudos sobre distribuição de renda e pobreza no Paraná}

Entre os diversos estudos que analisam a questão de desigualdade de renda no Paraná, pode ser destacado o trabalho de Ferreira e Souza (2007) que, a partir dos microdados das PNADs, calcularam o índice de Gini e sua decomposição para o Paraná no período de 2001 a 2005, mostrando a melhora na distribuição da renda paranaense e a importância dos rendimentos oriundos do trabalho para a definição desse indicador naquele quartel, conforme também aludido em Cunha e Vasconcelos (2011) para o intervalo de 1995 a 2008. Em Souza e Ferreira (2012), os autores atualizaram sua investigação com dados das PNADs de 2006 e 2009, concluindo pela manutenção da estrutura de renda e pela continuidade da melhora na desigualdade da distribuição de renda no Paraná. No entanto, destacaram a 
importância crescente dos rendimentos oriundos de pensões e aposentadorias para os domicílios situados nas menores faixas de renda.

Também utilizando microdados das PNADs, Souza et al. (2017) analisaram especificamente o papel dos rendimentos do trabalho para o comportamento da desigualdade na distribuição de renda no Paraná nos anos de 2002 e 2011. A partir de estimativas do índice de Gini, concluíram pela redução dos níveis de desigualdade da distribuição de renda entre 2002 e 2011 e destacaram a contribuição da melhora nas condições do mercado de trabalho para esse processo, especialmente via o avanço de distribuição da renda dos empregados dos setores privados.

Já Araújo et al. (2008) estimaram as desigualdades na distribuição de renda nos três estados da região Sul usando o índice de Theil-T calculado a partir dos dados das PNADs de 1995, 1999 e 2002-2006. Também verificaram queda na desigualdade da distribuição de renda do Paraná ao longo do período, mas ressaltando que o Paraná alcançou os menores avanços nos níveis de redução da desigualdade entre os estados da região.

Com o uso da metodologia de econometria espacial, Silva et al. (2013) aferiram a distribuição geográfica da pobreza entre os 399 municípios paranaenses utilizando dados do Censo de 2010. Os autores encontraram que 9,4\% dos domicílios paranaenses poderiam ser classificados como pobres (definidos como aqueles com renda domiciliar per capita de até $\mathrm{R} \$ 140,00)$, tendo a maior concentração desses domicílios nos municípios das regiões centro-sul e litorânea do estado, formando "clusters" espaciais de pobreza.

Por meio da mesma metodologia, mas avaliando dados referentes aos três estados da região Sul do Brasil referentes aos anos de 1991 e 2000, Cancian et al. (2013) apresentaram conclusões concernentes à distribuição da pobreza entre os municípios paranaenses semelhantes às expostas em Silva et al. (2013). Por sua vez, Couto et al. (2015) usaram dados das PNADs de 2003 e de 2013 para analisar a evolução da pobreza no Paraná no período. Tais autores definiram como pobres os domicílios com renda per capita inferior ao valor de meio salário-mínimo nacional vigente em setembro de 2013 (R\$ 678,00). A partir dessa linha de corte, os autores separaram os domicílios paranaenses em dois grupos, os pobres e os não pobres, e indicaram queda na proporção de indivíduos pobres no estado, de $35 \%$, em 2003, para 11\%, em 2013, tomando como base dados dos indivíduos de referência em cada domicílio. Também apontaram melhora na distribuição de 
renda, conforme medido pelo índice de Gini, mas ressaltaram a permanência de significativa diferença entre a renda média dos não pobres e pobres, sendo esta inferior à $20 \%$ daquela.

Todos os trabalhos acima utilizaram determinado nível de renda monetária, individual ou domiciliar, para definir uma situação de pobreza, ou seja, usaram uma abordagem unidimensional. Mas outros estudos procuraram tratar do fenômeno de pobreza no Paraná utilizando a denominada abordagem multidimensional, na qual outros aspectos, além da renda, são considerados para se mensurar e estabelecer condições de pobreza. Nóbrega (2008), por exemplo, usou microdados do Censo 2000 para definir e estimar indicadores de pobreza, tanto em termos monetários quanto multidimensionais, sendo este consolidado no conceito de índice de pobreza humana municipal (IPH-M), desenvolvido por Rolim et al. (2006), para os municípios dos estados do Paraná e de Sergipe. Usando a metodologia de Análise Exploratória de Dados Espaciais, o autor apontou a concentração de pobreza em municípios com baixa complexidade em suas estruturas econômicas e, em geral, desvinculados dos polos urbanos mais dinâmicos.

Munhoz (2009) utilizou a mesma base de dados (Censo 2000) e o conceito IPH-M para averiguar a distribuição de pobreza no Paraná. Ademais, definiu o valor de meio salário-mínimo como linha de pobreza, conforme linha de indigência definida em Rocha (2003), e, para a construção do seu índice multidimensional, acrescentou as variáveis concernentes aos índices FIRJAM de desenvolvimento econômico (IFD-M) e de desenvolvimento humano municipal (IDH-M). A autora concluiu que o IPH-M se mostrou mais adequado para a identificação da pobreza, especialmente pela importância dada nesse indicador aos aspectos relacionados à educação. Dadas as similaridades entre bases de dados e metodologias entre os trabalhos de Nóbrega (2008) e Munhoz (2009), as regiões identificadas como sendo as mais pobres em território paranaense se assemelharam.

Não há, porém, em Nóbrega (2008) e Munhoz (2009), discussão sobre a evolução temporal da pobreza no estado paranaense. Isso ocorre, por sua vez, em Albuquerque e Cunha (2012), que, a partir de dados das PNADs, utilizaram 21 variáveis, agrupadas em seis diferentes dimensões (condições habitacionais, saneamento, educação, trabalho, renda e demografia), para elaborar e mensurar um indicador multidimensional de pobreza no Paraná para os anos de 1995 e 2009. As autoras encontraram evidências de queda da pobreza entre a população do estado 
no período analisado, mas destacaram a importância que a dimensão trabalho pareceu ter para a saída da condição de pobreza.

Conforme exposto nesta seção, diversos trabalhos, por meio de diferentes metodologias, têm indicado redução da desigualdade de renda e da pobreza no Paraná. Nenhum, porém, estendeu sua análise por um período de duas décadas e, por consequência, abrangeu diversos ciclos econômicos, chegando inclusive à fase recessiva mais recente tal qual o presente artigo. Da mesma forma, os trabalhos abordaram aspectos relacionados à desigualdade de renda ou à pobreza, sem relacionar os dois fenômenos. No entanto, como apontou Rocha (2003), o Brasil deve ser considerado um país de renda média e, em tal condição, o fenômeno da pobreza decorre ou está fortemente relacionado à desigualdade na distribuição da renda. No Paraná, tal escolha analítica, avaliar conjuntamente desigualdade de renda e pobreza, reforça-se e os avanços já observados não podem implicar esmorecimento na discussão e formulação de ações combativas a tais problemas, pois, como discutido na seção 4, o estado ainda apresenta um quadro desfavorável na comparação internacional.

\section{Fonte de dados e procedimentos metodológicos}

Para analisar a evolução da desigualdade na distribuição da renda e da pobreza no Estado do Paraná, são utilizados os dados da Pesquisa Nacional por Amostra de Domicílios do Instituto Brasileiro de Geografia e Estatística de 1995 até 2015, excetuando-se os anos de 2000 e 2010 quando as pesquisas não foram realizadas, em função destes serem anos censitários.

Na análise da desigualdade na distribuição da renda, foi considerada a renda domiciliar per capita, excluindo-se do total de moradores dos domicílios os indivíduos classificados como pensionistas, empregados domésticos e parentes do empregado doméstico. Com isso, buscou-se estimar efetivamente a renda da unidade familiar residente em um mesmo domicílio. Os valores dos rendimentos foram corrigidos para setembro de 2015, com base no deflator para as PNADs, disponibilizado pelo Instituto de Economia Aplicada (IPEA) e construído de acordo com metodologia proposta por Corseuil e Foguel (2002).

O comportamento da desigualdade na distribuição de renda é calculado por meio de estimativas dos índices de Gini, $T$ de Theil e $L$ de Theil. Assim, seguindo Hoffmann (1998), considere uma população com $n$ domicílios, com a renda do 
$i$-ésimo domicílio denotada por $x_{i}$ e com a renda média representada por $\mu$. $\mathrm{O}$ índice de desigualdade de Gini $(G)$ pode ser expresso por:

$$
G=\frac{2}{n^{2} \mu} \sum_{i=1}^{n} i x_{i}-\left(1+\frac{1}{n}\right)
$$

Por sua vez, sendo a fração da renda total correspondente ao $i$-ésimo domicílio:

$$
y_{i}=\frac{x_{i}}{n \mu}
$$

torna-se possível calcular os índices $T$ de Theil $\left(I_{0}\right)$ e $L$ de Theil $\left(I_{1}\right)$ por meio das seguintes equações:

$$
\begin{aligned}
& I_{0}=\frac{1}{n} \sum \log \left(\frac{1}{n y_{i}}\right) \\
& I_{1}=\sum_{i} y_{i} \log \frac{y_{i}}{\frac{1}{n}}
\end{aligned}
$$

É importante ressaltar que os três indicadores estimados e apresentados refletem distintos aspectos da distribuição de renda. O índice de Gini é mais sensível a mudanças na moda da distribuição de renda, enquanto o $T$ de Theil é mais sensível a alterações na cauda superior da distribuição de renda e o $L$ de Theil na cauda inferior, portanto, entre os mais pobres (HOFFMANN, 1998). Adicionalmente, é também obtida a proporção da renda acumulada pelos $50 \%$ mais pobres e pelos $10 \%, 5 \%$ e $1 \%$ mais ricos.

Os índices de Theil podem ser decompostos para diferentes grupos da população e utilizados para explicarem se a evolução da desigualdade é resultado principalmente das variações de desigualdade dentro desses grupos ou entre esses grupos $^{2}$. Essa parcela da desigualdade entre grupos representa a contribuição dessa característica ou determinante para a explicação da desigualdade total. Assim, a subdivisão da população em grupos se constitui em um importante instrumento de análise da desigualdade, uma vez que pode indicar as origens das mutações nessa variável.

Neste trabalho é obtida a decomposição do índice $T$ de Theil para a subdivisão da população considerando quatro características da pessoa de

\footnotetext{
${ }^{2}$ Para maiores detalhes, ver Hoffmann (1998).
} 
referência do domicílio, ou seja, gênero, cor, idade e educação, além de duas características da residência, se situada na região metropolitana de Curitiba ou não e se localizada em área urbana ou em área rural. Enquanto os fatores relacionados à localização do domicílio têm cada um dois grupos, para a idade, são considerados cinco grupos etários (até 24 anos, de 25 até 34 anos, de 35 até 49 anos, de 50 até 64 anos e de 65 anos ou mais); para a educação, seis grupos (menor que 1 ano de escolaridade, de 1 até 3 anos, de 4 até 7 anos, de 8 até 10 anos, de 11 até 14 anos e com 15 anos ou mais); para cor dos indivíduos, dois grupos (os brancos, que incluem brancos e amarelos, e os não brancos com negros, pardos e indígenas); e, por fim, para gênero, dois grupos (homens e mulheres).

Para a análise da pobreza, é considerada uma linha igual ao valor $\mathrm{R} \$ 154,00$ para o rendimento domiciliar per capita, que corresponde ao valor utilizado pelo Programa Bolsa Família ao longo do ano de 2015, último ano avaliado neste trabalho. Por sua vez, a metade desse valor, $\mathrm{R} \$ 77,00$, é definida como linha de extrema pobreza. Tais limites são mantidos constantes ao longo da série, pois todos os valores nominais utilizados nas estimativas estão corrigidos pelo deflator da PNAD a valores de setembro de 2015. A partir disso, são calculadas três medidas de pobreza: a proporção de pobres, a insuficiência de renda e a severidade da pobreza. Essas três medidas se constituem em casos especiais do Índice de Foster, Greer e Thorbecke (FGT), conforme Hoffmann (1998), dado por:

$$
F G T(\alpha)=\frac{1}{n z^{\alpha}} \sum_{i=1}^{p}\left(z-x_{i}\right)^{\alpha}
$$

em que a proporção de pobres é dada para $F G T(\alpha=0)$, o índice que capta a insuficiência de renda é obtido quando $F G T(\alpha=1)$ e, por fim, o índice de severidade da pobreza corresponde ao $F G T(\alpha=2)$.

A proporção de pobres se constitui em uma medida de extensão da miséria, não sendo sensível à intensidade da pobreza. Dessa forma, se a renda de uma pessoa pobre cair, essa medida de pobreza não é alterada. A medida para a insuficiência de renda corresponde à soma da diferença entre o valor da linha de pobreza e o rendimento de cada domicílio, abaixo ou na linha de pobreza, dividida pelo valor máximo dessa diferença, que corresponde ao número de domicílios pobres multiplicado pelo valor da linha de pobreza. Para Neder e Silva (2003), essa medida representa o 'déficit de pobreza', ou seja, o quanto de renda seria necessário para elevar as famílias à linha de pobreza, portanto considera a intensidade da pobreza. 
Por sua vez, o índice de severidade da pobreza leva em consideração a extensão, a intensidade e a desigualdade na distribuição de rendimentos entre os pobres. Esse índice dá maior importância para a situação dos mais pobres entre os pobres e é sensível à distribuição de renda entre estes, uma vez que é obtido quando se eleva ao quadrado o indicador de intensidade da pobreza.

Ressalta-se que, para o cálculo dos indicadores de desigualdade e de pobreza, foi considerada a população estimada a partir dos pesos disponibilizados na PNAD. Ademais, para homogeneização e comparação dos resultados ao longo do período, os domicílios com alguma informação incompleta sobre as variáveis utilizadas no estudo, tais como rendimentos, escolaridade, idade e cor foram desconsiderados. Após essas exclusões, considerando para exemplificação apenas os anos extremos no período analisado, têm-se, em 1995, 5.483 domicílios na amostra e 2.276.783 na população estimada e, em 2015, 6.514 domicílios e 3.875.803 na população estimada.

\section{Evolução da desigualdade na distribuição da renda domiciliar}

Conforme a Tabela 1, o rendimento domiciliar médio per capita no Paraná oscilou em torno de $\mathrm{R} \$ 960,00$ entre 1995 a 2003, mas, a partir de 2004, passou a ter uma trajetória ascendente, com interrupção momentânea apenas em 2008, até 2014. Seguindo a tendência observada para o Brasil, as medidas de desigualdade na distribuição da renda domiciliar para o Paraná indicam arrefecimento no período. O índice de Gini era de 0,586 em 1995, caindo para 0,473 em 2015, ainda que tenham sido observadas elevações em relação aos períodos imediatamente anteriores no final da década de 1990, em 2003, 2012 e 2015. A melhora também se refletiu na proporção da renda acumulada pelos $50 \%$ mais pobres, que aumentou de $13,4 \%$ para $19,9 \%$, enquanto as rendas acumuladas pelos $10 \%$, $5 \%$ e $1 \%$ mais ricos sofreram reduções.

Como mostrado na Tabela 1, as mudanças na distribuição de renda entre os percentis do domicílio foram significativas ao longo do período avaliado. Nos primeiros anos da série, a renda acumulada do $1 \%$ dos domicílios paranaenses mais ricos era superior à renda total auferida pelos $50 \%$ mais pobres, mas, em 2015, a parcela destes na renda total passa a ser o dobro da detida por aqueles. Ademais, proporcionalmente, a queda no indicador de desigualdade da renda domiciliar se mostra mais intensa no L Theil, ou seja, na cauda inferior da renda. Tal fenômeno, 
possivelmente, está relacionado com os decréscimos nos diferenciais de salários, conforme apontado em Cunha e Vasconcelos (2011) e Souza et al. (2017), por sua vez explicados, segundo tais autores, pelos avanços na escolaridade média e pelo ciclo econômico expansivo observado ao longo da década de 2000. No entanto, as proporções acumuladas pelos mais ricos em detrimento dos mais pobres ainda revelam profundas disparidades.

Tabela 1 - Medidas de desigualdade da distribuição da renda domiciliar per capita, Paraná, 1995-2015

\begin{tabular}{lrrrrrrrr}
\hline Ano & Média & Gini & $\boldsymbol{T}$ & $\boldsymbol{L}$ & $\mathbf{5 0}^{-}$ & $\mathbf{1 0}^{+}$ & $\mathbf{5}^{+}$ & $\mathbf{1}^{+}$ \\
\hline 1995 & 948,19 & 0,586 & 0,699 & 0,609 & 0,134 & 0,469 & 0,333 & 0,136 \\
1996 & 978,94 & 0,586 & 0,723 & 0,598 & 0,136 & 0,474 & 0,340 & 0,144 \\
1997 & 921,24 & 0,571 & 0,663 & 0,552 & 0,141 & 0,454 & 0,321 & 0,129 \\
1998 & 946,51 & 0,575 & 0,677 & 0,565 & 0,140 & 0,459 & 0,324 & 0,136 \\
1999 & 925,08 & 0,584 & 0,682 & 0,584 & 0,136 & 0,469 & 0,334 & 0,125 \\
2001 & 1034,89 & 0,563 & 0,661 & 0,537 & 0,149 & 0,456 & 0,331 & 0,135 \\
2002 & 973,84 & 0,543 & 0,588 & 0,509 & 0,157 & 0,432 & 0,301 & 0,117 \\
2003 & 967,95 & 0,557 & 0,679 & 0,533 & 0,155 & 0,455 & 0,334 & 0,150 \\
2004 & 1040,61 & 0,550 & 0,638 & 0,521 & 0,156 & 0,444 & 0,321 & 0,136 \\
2005 & 1059,64 & 0,540 & 0,597 & 0,500 & 0,160 & 0,431 & 0,305 & 0,123 \\
2006 & 1120,41 & 0,526 & 0,578 & 0,480 & 0,170 & 0,423 & 0,301 & 0,128 \\
2007 & 1234,69 & 0,526 & 0,578 & 0,466 & 0,170 & 0,424 & 0,298 & 0,127 \\
2008 & 1218,68 & 0,506 & 0,517 & 0,422 & 0,180 & 0,405 & 0,282 & 0,110 \\
2009 & 1233,91 & 0,495 & 0,479 & 0,404 & 0,184 & 0,392 & 0,267 & 0,100 \\
2011 & 1299,97 & 0,470 & 0,437 & 0,356 & 0,199 & 0,369 & 0,253 & 0,099 \\
2012 & 1414,68 & 0,479 & 0,473 & 0,374 & 0,197 & 0,386 & 0,270 & 0,109 \\
2013 & 1491,56 & 0,474 & 0,464 & 0,363 & 0,199 & 0,378 & 0,261 & 0,107 \\
2014 & 1496,55 & 0,457 & 0,410 & 0,351 & 0,207 & 0,364 & 0,246 & 0,091 \\
2015 & 1442,71 & 0,473 & 0,444 & 0,376 & 0,199 & 0,380 & 0,265 & 0,099 \\
\hline
\end{tabular}

Fonte: Elaboração própria a partir das informações básicas das PNADs.

A alta discrepância na distribuição da renda domiciliar paranaense fica evidente quando se observam algumas relações entre os décimos e percentis, como mostra a Figura 1. Observa-se na Figura 1 (a) a relação entre os $10 \%$ mais ricos e os $10 \%$ mais pobres. Em 1995, os $10 \%$ mais ricos detinham 58,6 vezes a renda dos $10 \%$ mais pobres, mas, ao longo do período, essa relação se reduziu e alcançou 25,6 vezes em 2015. Por sua vez, na Figura 1 (b), a relação entre os $10 \%$ mais ricos e os $50 \%$ mais pobres aponta que os primeiros detinham 3,5 vezes a renda dos $50 \%$ mais pobres em 1995, e que, em 2015, essa relação decresceu para 1,9. 
Mas se os avanços foram significativos para a queda das disparidades de renda no Paraná, os indicadores ainda apontam para um cenário de elevada desigualdade conforme padrões internacionais. Segundo Luebker (2009), os coeficientes de Gini para os países com baixa desigualdade seriam em torno de 0,20 e com moderada, alta e extremamente alta desigualdades, iguais a 0,25, 0,35 e 0,50 , respectivamente. Já as rendas acumuladas pelos $10 \%$ mais ricos deveriam ser no máximo iguais a 17,8\%,20,3\%,26,1\% e 37,2\%, seguindo a mesma ordem de classificação. Para Piketty (2014), os índices de Gini para os países com baixa, média, acentuada e muito acentuada desigualdade na distribuição da renda do trabalho seriam de, respectivamente, $0,19,0,26,0,36$ e 0,46 . E os $10 \%$ mais ricos, os $40 \%$ seguintes e os $50 \%$ mais pobres deveriam deter cerca de $20 \%$, $45 \%$ e $35 \%$ da renda nos países com baixa desigualdade, e 45\%, 35\% e 20\% naqueles classificados com acentuada desigualdade.

Figura 1 - Evolução das relações entre os 10+ e 10-, 10+ e 50- e 1+- e 50-, Paraná, 1995-2015

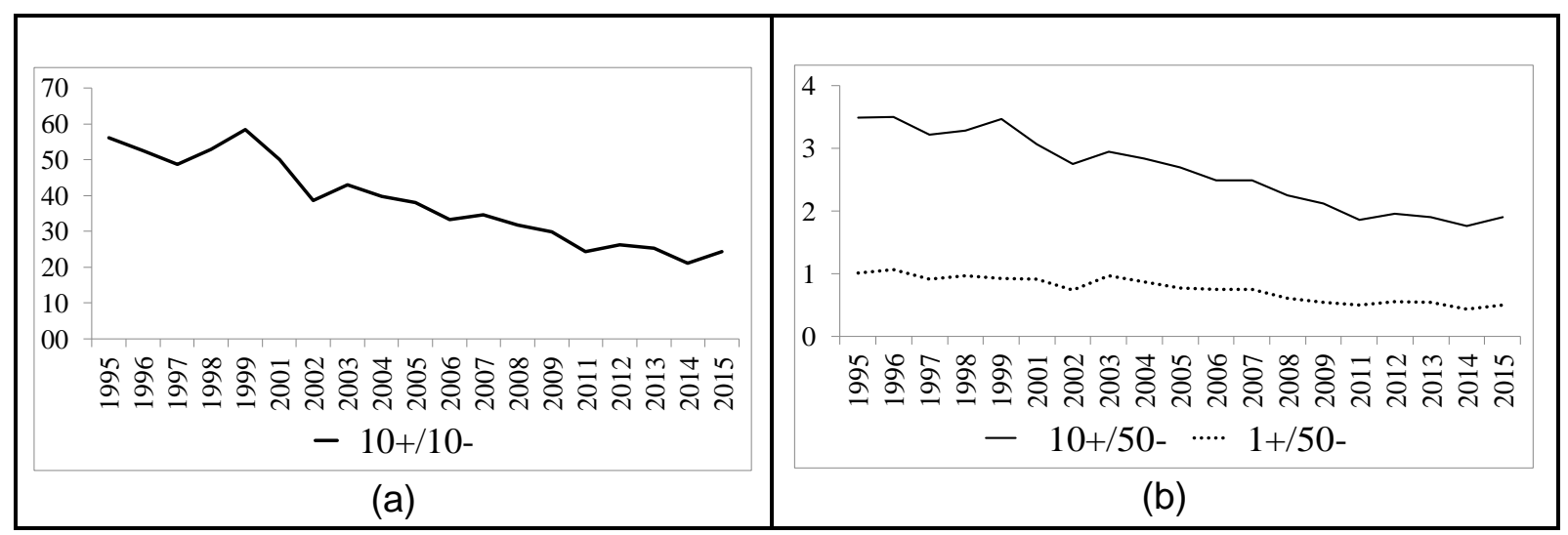

Fonte: elaboração própria a partir das informações básicas das PNADs.

Nesse sentido, usando os critérios de Piketty (2014) e Luebker (2009), é possível classificar o estado do Paraná como uma sociedade situada entre alta e extremamente desigual. Em 2015, o Paraná apresentava um índice de Gini igual a 0,473 e as rendas apropriadas pelos domicílios $10 \%$ mais ricos, os $40 \%$ seguintes e os $50 \%$ mais pobres eram equivalentes a $38,0 \%, 42,1 \%$ e $19,9 \%$, respectivamente.

Conforme dados da OCDE, em 2015, o México aparecia como o país membro com o pior indicador de distribuição de renda, com um índice de Gini de 
0,459, seguido pelo Chile, com 0,454. Já os $20 \%$ mais ricos desses dois países possuíam 10,4 e 10,0 vezes, respectivamente, mais renda acumulada do que os $20 \%$ mais pobres. No Paraná, essa mesma relação é de 10,8 vezes. Se considerarmos um país da OCDE em posição média entre seus membros, como a Polônia, por exemplo, a comparação torna-se ainda mais desfavorável, já que tal país apresenta um índice de Gini de 0,298 e os $20 \%$ mais ricos detêm apenas 4,6 vezes mais renda do que os $20 \%$ mais pobres. Portanto, no quesito de distribuição de renda, o Paraná apresenta números ainda desfavoráveis mesmo quando comparados aos das nações de médio desenvolvimento situadas na América Latina.

\section{Principais características da desigualdade na distribuição da renda domiciliar}

A importância de características socioeconômicas para a determinação da desigualdade na distribuição da renda pode ser observada na Tabela 2. Nela estão expostas a decomposição da desigualdade na distribuição do rendimento domiciliar considerando o índice $T$ de Theil, além da proporção de domicílios em cada categoria, seu rendimento domiciliar per capita médio e o valor do índice de Theil em cada componente. A proporção da desigualdade entre grupos corresponde ao valor da contribuição da desigualdade total explicada pelas diferenças entre os grupos em cada característica domiciliar analisada. Assim, buscando compreender a desigualdade na distribuição do rendimento domiciliar, foram consideradas alguns atributos pessoais do chefe do domicílio, como sexo, cor, idade, anos de estudo, e também características de localização do domicílio, se situado na região metropolitana ou não e na zona rural ou na zona urbana.

Em 1995, o percentual de homens chefes de domicílio era consideravelmente maior do que o de mulheres chefes, $83 \%$ e $17 \%$, respectivamente. Porém verificou-se redução nessa disparidade ao longo do período: em 2015, o percentual de domicílios paranaenses que tinham o homem como chefe caiu para $64 \%$ e o de mulheres subiu para $36 \%$. Por outro lado, em relação ao rendimento domiciliar médio, no início do período, observou-se diferencial favorável às mulheres, com o rendimento nos domicílios chefiados por homens igual a $\mathrm{R} \$ 954,40$ e, por mulheres, de $\mathrm{R} \$ 975,36$. Ao final do período, no entanto, a situação se inverteu e os domicílios chefiados por elas passaram a apresentar rendimento médio inferior aos dos homens. De acordo com o índice de 
Theil, a desigualdade na distribuição da renda entre os domicílios chefiados por mulheres era superior à dos homens em 1995, situação que se inverteu em 2005, mas voltou a se manifestar em 2015, embora ambos os grupos tenham apresentado reduções nessa desigualdade. Ademais, a importância da desigualdade de gênero, entre grupos, na disparidade total teve aumento no período.

Tabela 2 - Proporção dos domicílios e do rendimento domiciliar per capita e o índice de Theil em subgrupos - Paraná (1995-2015)

\begin{tabular}{|c|c|c|c|c|c|c|c|c|c|}
\hline \multirow{2}{*}{ Variável } & \multicolumn{3}{|c|}{$\begin{array}{c}\text { Proporção de } \\
\text { domicílios }\end{array}$} & \multicolumn{3}{|c|}{$\begin{array}{l}\text { Rendimento } \\
\text { Médio }\end{array}$} & \multicolumn{3}{|c|}{$\begin{array}{c}\text { Desigualdade } \\
\text { ( } T \text {-Theil) }\end{array}$} \\
\hline & 1995 & 2005 & 2015 & 1995 & 2005 & 2015 & 1995 & 2005 & 2015 \\
\hline \multicolumn{10}{|l|}{ Sexo } \\
\hline Homens & 0,83 & 0,74 & 0,64 & 954,40 & 1044,46 & 1476,72 & 0,683 & 0,617 & 0,441 \\
\hline Mulheres & 0,17 & 0,26 & 0,36 & 975,36 & 1103,59 & 1382,70 & 0,719 & 0,540 & 0,448 \\
\hline \multicolumn{4}{|c|}{ Desigualdade entre grupos $(\%)$} & & & & 0,00 & 0,05 & 0,11 \\
\hline \multicolumn{10}{|c|}{ Cor } \\
\hline Não branco & 0,24 & 0,27 & 0,31 & 536,78 & 641,79 & 1048,11 & 0,466 & 0,380 & 0,365 \\
\hline Bran & 0,76 & 0,73 & 0,69 & 1091,17 & 1214,92 & & 0,684 & 0,601 & 0,444 \\
\hline \multicolumn{4}{|c|}{ Desigualdade entre grupos $(\%)$} & & & & 5,04 & 5,36 & 4,07 \\
\hline \multicolumn{10}{|c|}{ Educação } \\
\hline Meno & 0,17 & 0,12 & 0,10 & 380,82 & 513,57 & 839,35 & 0,294 & 0,209 & 0,176 \\
\hline 1 at & 0,22 & & & & & & 0,344 & 0,363 & 223 \\
\hline 4 at & 0,32 & & 3 & & 655 & & 0,391 & 0,353 & 0,247 \\
\hline 8 at & 0,11 & 0 , & 14 & & & & 0,519 & 0,330 & 0,260 \\
\hline $11 \mathrm{a}$ & 0,12 & 0,22 & 0,30 & 86 & 1397 & & 0,377 & 0,414 & 0,315 \\
\hline 15 anos ou mais & 0,06 & 0,08 & 0,13 & 4040,57 & 3614,31 & 3518 & 0,370 & 0,395 & 0,373 \\
\hline \multicolumn{4}{|c|}{ Desigualdade entre grupos (\%) } & & & & 44,05 & 37,47 & 31,42 \\
\hline \multicolumn{10}{|c|}{ Idade } \\
\hline Até 24 & 0,06 & 0,05 & 0,04 & & & & 0,471 & 0,544 & 0,422 \\
\hline & 0,25 & & 0,17 & 906,89 & & & 0,601 & 0,592 & 0,482 \\
\hline & 0,35 & $0, ?$ & 0,30 & 1003,18 & 959 & & 0,683 & 0,517 & 0,421 \\
\hline & 0,22 & & 0,30 & 1054,74 & 129 & & 0,809 & 0,674 & 0,451 \\
\hline 65 ou mais & 0,12 & 0,14 & 0,18 & 883,02 & 1141,50 & 1494,47 & 0,675 & 0,571 & 0,396 \\
\hline \multicolumn{4}{|c|}{ Desigualdade entre grupos (\%) } & 1,00 & & & 0,68 & 1,70 & 1,74 \\
\hline \multicolumn{10}{|c|}{ Região } \\
\hline Metropo & 0,74 & & & & & & 0,617 & 0,576 & 0,400 \\
\hline Metropolitana & 0,26 & 0,29 & 0,31 & 1539,23 & 1373,10 & 1789,23 & 0,652 & 0,586 & 0,482 \\
\hline \multicolumn{4}{|c|}{ Desigualdade entre grupos (\%) } & & & & 8,34 & 2,89 & 2,83 \\
\hline \multicolumn{10}{|c|}{ Domicílio } \\
\hline Rural & 0,20 & 0, & 0,1 & & & & 0,449 & & 0,303 \\
\hline Urbano & 0,80 & 0,85 & 0,88 & 1096,31 & 1153,14 & 1507,62 & 0,655 & 0,587 & 0,448 \\
\hline \multicolumn{4}{|c|}{ Desigualdade entre grupos (\%) } & & & & 7,40 & 4,26 & 1,86 \\
\hline
\end{tabular}

Fonte: elaboração própria a partir das informações básicas das PNADs.

A proporção de chefes brancos em relação aos não brancos, embora em queda, ainda é expressivamente maior, com 76\% de brancos, em 1995, e 69\%, em 
2015. Esses resultados estão de acordo com a formação da população paranaense. Ademais, ao contrário da relação de homens e mulheres, ocorreu redução na disparidade de renda domiciliar considerando tal característica, que em 2015 contribuiu com $4,07 \%$ da desigualdade total.

Quanto ao rendimento médio, pode ser observado um forte diferencial de raça, embora decrescente no período: em 1995, os domicílios chefiados por brancos tinham um rendimento $103,3 \%$ superior ao dos não brancos; mas, em 2015, essa superioridade caiu para 54,8\%. A desigualdade na distribuição da renda entre os brancos, em 1995, era maior do que a desigualdade entre os não brancos e se manteve assim em 2005 e 2015 . Houve, porém, queda da desigualdade para os dois casos, com mais significativa redução para os brancos, de 35,1\%. Além disso, a proporção da desigualdade explicada pela diferença de rendimentos entre os domicílios chefiados por brancos e não brancos teve decréscimo, mas se mostra superior à obtida entre os sexos, 4,07\% ante 0,11\% em 2015.

Seguindo a tendência observada para o Brasil de aumento dos anos de escolaridade, no Paraná, em 1995, aproximadamente 18\% dos domicílios eram chefiados por indivíduos com 11 anos ou mais de estudo, enquanto, em 2015, tal percentual se elevou para $43 \%$. Em contrapartida, todas as faixas com até 7 anos de estudo apresentaram redução na proporção de chefes de família no período. Já as faixas com 8 anos ou mais de estudo mostraram ascensões, especialmente o percentual dos chefes de família com a maior faixa de estudo, de 15 anos ou mais. O rendimento domiciliar per capita médio em domicílios cujos chefes tinham menos anos de estudo exibiu aumento, enquanto naqueles cujos chefes apresentavam mais anos de estudo sofreu retração, ou seja, ocorreu uma convergência de renda entre esses dois grupos, refletindo a queda no prêmio por escolaridade. Além disso, à exceção dos mais escolarizados (15 anos ou mais), todas as faixas de anos de estudo apresentaram declínio na desigualdade. Assim, o aumento da escolaridade parece ter contribuído para o decréscimo da desigualdade na distribuição de renda domiciliar no período. Isso corrobora com a redução significativa da contribuição da escolaridade para a explicação da desigualdade na distribuição de renda domiciliar total: de 44,05\% a 31,42\%, de 1995 para 2015.

No início do período do estudo, 66\% dos chefes tinham até 49 anos e os demais 34\% apresentavam 50 anos ou mais. Em 2015, houve contração nas faixas de idade até 49 anos, para 51\%, e acréscimo do percentual nas faixas de idade acima 
de 49 anos, para 49\%, o que está de acordo com o envelhecimento da população brasileira. Em relação ao rendimento domiciliar per capita médio, observou-se, em 1995, que, até os 64 anos, quanto mais alta a faixa de idade maior o rendimento. Por sua vez, em 2015, a tendência de aumento era até a faixa dos 25 a 34 anos, interrompido com redução na faixa de 35 até 49 anos, mas voltando a subir e atingindo o valor máximo na penúltima faixa de idade (49 a 64 anos), e, tal qual o verificado para o ano de 1995, queda no grupo com mais de 65 anos. A desigualdade apresentou no início do período tendência ascendente até 64 anos, mas com leve descenso a partir dos 65 anos. Em 1995, essa perda era de 16,6\% e se reduziu para $12,2 \%$ no último ano da série. Embora isso possa estar associado a um maior contingente de pessoas se mantendo ativo no mercado de trabalho e, assim, elevando a renda média domiciliar dos chefes acima de 64 anos, o mais provável é que esteja relacionado com os ganhos observados nas aposentadorias vinculadas à correção do salário-mínimo real, que apresentou valores médios anuais crescentes desde 1995 e cuja tendência se ampliou a partir de 2004 até $2012^{3}$.

É destaque também no período o ganho de participação dos domicílios localizados na região Metropolitana de Curitiba. Segundo os dados da PNAD, a proporção de domicílios paranaenses nessa região metropolitana, em 1995, era de $26 \%$, enquanto que $74 \%$ estava localizada em outras regiões do estado; já em 2015 , esses percentuais eram de $31 \%$ e $69 \%$, respectivamente ${ }^{4}$. No entanto, a superioridade dos valores médios de renda domiciliar dessa região em relação ao restante do estado sofreu redução. Em 1995, o rendimento domiciliar per capita na Região Metropolitana de Curitiba era 103,3\% superior ao das regiões restantes do estado, caindo para 39,2\% em 2015. Ou seja, outro caso de convergência de renda domiciliar observada no Paraná. Apesar de o rendimento médio ser maior, a desigualdade na distribuição de renda na região metropolitana foi superior nos três anos em destaque e, mesmo que em queda, essa foi relativamente inferior à observada no indicador de desigualdade do restante do estado. Diante desse quadro, a contribuição da região de residência para explicar a desigualdade total caiu de 8,34\%, em 1995, para 2,83\%, em 2015.

\footnotetext{
${ }^{3}$ Segundo série do IPEADATA, com salários-mínimos deflacionados pelo INPC/IBGE, entre 1994 e 2003 , o valor real médio anual do salário-mínimo cresceu à taxa de 3,2\% a.a. Nos nove anos seguintes, abrangendo o período de 2004 a 2012, esta taxa subiu para $6,1 \%$ a.a.

${ }^{4}$ Nos números da PNAD apenas a região metropolitana da capital do estado entra nessa categoria.
} 
Em 1995, os percentuais de domicílios na zona rural e na zona urbana eram de $20 \%$ e $80 \%$, respectivamente, e, até o final do período estudado, em 2015 , observou-se encolhimento para 12\% nos domicílios em áreas rurais. A renda média dos domicílios da zona urbana era mais do que duas vezes superior à renda dos situados em zona rural, mas, no período, ocorreu expressiva redução nessa disparidade. Em 2015, em média, os domicílios da zona urbana tinham um rendimento $55,7 \%$ superior ao de um da zona rural, mas, em 1995, tal superioridade alcançava 172,5\%. Portanto, também se observou um movimento de convergência da renda média domiciliar entre as áreas urbanas e rurais. Ademais, a desigualdade na distribuição de renda na zona rural era expressivamente menor do que na zona urbana. Observou-se encolhimento da desigualdade nas zonas rurais e urbanas e da sua contribuição para explicar a disparidade total de $7,40 \%$, em 1995, para $1,86 \%$ em 2015.

Portanto, com exceção dos elementos relacionados a gênero e faixa etária, a análise, conforme as características dos chefes dos domicílios e da localização destes, indica contração da desigualdade entre todos os grupos de cor, anos de estudo, região metropolitana e não metropolitana e zona urbana e rural. Observa-se a convergência dos níveis de renda domiciliar em muitas das características analisadas, tais como extremos de anos de escolaridade e a localização dos domicílios. Destaca-se a importância, embora decrescente, da escolaridade para explicar a desigualdade total, em 31,4\% em 2015, refletindo a alta disparidade educacional do país e do Paraná, e a relevância da continuidade dos investimentos públicos em educação de qualidade voltados para as parcelas mais desfavorecidas da população.

\section{Comportamento e perfil socioeconômico da pobreza paranaense}

Nos primeiros 15 anos do século XXI, é possível constatar contração do percentual de domicílios paranaenses em situação de pobreza, conforme pode ser verificado na Tabela 3. Se na segunda metade da década de 1990 os percentuais de domicílios classificados como pobres eram superiores a $10 \%$, posteriormente, no decorrer dos anos, ocorreram seguidos decréscimos até a crise econômica e política em 2014, quando chegou a atingir o menor valor da série, apenas 1,8\%, voltando a subir, em 2015, para pouco mais de 2,4\%. Nota-se também uma significativa queda do déficit de pobreza, a partir dos anos 2000, porém com algumas interrupções na 
redução desse indicador. De 1999 a 2014, a contração no indicador foi de 79,6\%, chegando a 1,024 nesse último ano. Porém, em 2015, aumentou para 1,399.

De forma menos contínua também se constatou melhora no índice de severidade. Nesse indicador, é dado um peso maior para os mais pobres e se mensura a desigualdade entre os pobres. Sendo assim, e considerando o grande nível de vulnerabilidade social e econômica dessa parcela da população, verificouse involução desse índice durante períodos de crise econômica, como de 2002 para 2003, 2007 para 2008 e 2014 para 2015. Porém, observando-se todo o período, notou-se que, além de diminuir o percentual de domicílios classificados como pobres, foi igualmente atenuada a magnitude dessa pobreza.

\section{Tabela 3 - Medidas* de pobreza e de extrema pobreza para o rendimento domiciliar per capita - Paraná (1995-2015)}

\begin{tabular}{|c|c|c|c|c|c|c|}
\hline \multirow[b]{2}{*}{ Ano } & \multicolumn{3}{|c|}{ Pobreza } & \multicolumn{3}{|c|}{ Extrema pobreza } \\
\hline & $\begin{array}{c}\text { Proporção } \\
\text { de } \\
\text { Pobres }\end{array}$ & $\begin{array}{c}\text { Insuficiência } \\
\text { de } \\
\text { renda }\end{array}$ & $\begin{array}{l}\text { Índice de } \\
\text { severidade }\end{array}$ & $\begin{array}{c}\text { Proporção de } \\
\text { extremament } \\
\text { e } \\
\text { Pobres }\end{array}$ & $\begin{array}{c}\text { Insuficiência } \\
\text { de } \\
\text { renda }\end{array}$ & $\begin{array}{c}\text { Índice de } \\
\text { severidade }\end{array}$ \\
\hline 1995 & 12,795 & 5,019 & 3,008 & 4,245 & 1,937 & 1,484 \\
\hline 1996 & 10,647 & 4,275 & 2,586 & 3,418 & 1,724 & 1,346 \\
\hline 1997 & 11,063 & 4,427 & 2,881 & 3,559 & 2,123 & 1,783 \\
\hline 1998 & 10,638 & 4,684 & 3,036 & 3,648 & 2,122 & 1,766 \\
\hline 1999 & 12,290 & 5,302 & 3,522 & 4,424 & 2,614 & 2,156 \\
\hline 2001 & 8,712 & 3,945 & 2,773 & 3,475 & 2,157 & 1,858 \\
\hline 2002 & 8,424 & 3,043 & 1,849 & 2,314 & 1,269 & 1,025 \\
\hline 2003 & 8,256 & 3,404 & 2,210 & 2,494 & 1,619 & 1,393 \\
\hline 2004 & 6,794 & 2,876 & 1,906 & 2,239 & 1,439 & 1,213 \\
\hline 2005 & 6,409 & 2,666 & 1,776 & 2,226 & 1,362 & 1,128 \\
\hline 2006 & 5,080 & 1,958 & 1,253 & 1,481 & 0,915 & 0,758 \\
\hline 2007 & 4,016 & 1,990 & 1,499 & 1,741 & 1,267 & 1,142 \\
\hline 2008 & 3,959 & 2,125 & 1,730 & 2,010 & 1,541 & 1,417 \\
\hline 2009 & 3,845 & 2,045 & 1,642 & 1,921 & 1,458 & 1,334 \\
\hline 2011 & 2,690 & 1,834 & 1,615 & 1,902 & 1,520 & 1,400 \\
\hline 2012 & 2,503 & 1,736 & 1,533 & 1,748 & 1,442 & 1,348 \\
\hline 2013 & 2,437 & 1,763 & 1,570 & 1,655 & 1,447 & 1,386 \\
\hline 2014 & 1,812 & 1,024 & 0,830 & 0,924 & 0,741 & 0,683 \\
\hline 2015 & 2,430 & 1,399 & 1,237 & 1,390 & 1,014 & 0,895 \\
\hline
\end{tabular}

Nota: *As medidas de pobreza e extrema pobreza foram multiplicas por 100.

Fonte: elaboração própria a partir das informações básicas das PNADs.

A proporção da população em situação de extrema pobreza também apresentou contração a partir de 2001. No entanto, não foram contínuas no decorrer dos anos como a proporção de pobres, mas se deve destacar que, de 1999 até 2014 , 
acorreu retração de quase $80 \%$ no percentual dos extremamente pobres. No ano de 2015, o percentual subiu de aproximadamente 0,9\%, em 2014, para quase $1,4 \%$. Em relação à insuficiência de renda dos domicílios extremamente pobres, foi constatada a mesma situação observada para aqueles pobres, com redução de $71,5 \%$ no indicador entre 1999 e 2014 , embora com aumento de 0,741 para 1,014 no ano seguinte. A mesma situação verifica-se para o indicador de severidade da extrema pobreza, que também voltou a ascender de 2014 para 2015, embora ainda se encontrasse em um patamar inferior ao início do período estudado.

Assim, esses resultados sugerem que o crescimento econômico e as políticas adotadas em prol dos menos favorecidos contribuíram significativamente para a redução da população pobre e extremamente pobre, mas que tal processo pode ter sido interrompido pelas consequências da crise econômica e política no país no final do período estudado.

Com o objetivo de se fazer uma análise do perfil da pobreza no Paraná, são expostas, na Tabela 4, as características dos chefes e da localização dos domicílios pobres. São apresentadas as proporções de domicílios e de rendimento em cada subgrupo, bem como o rendimento domiciliar per capita médio. Note que foram consideradas as mesmas características da Tabela 2, o que permite traçar um paralelo do perfil dos domicílios pobres em relação ao total de domicílios no estado.

No Paraná, os rendimentos domiciliares per capita médios nos domicílios pobres nos anos de 1995, 2005 e 2015 foram iguais a $R \$ 93,58, R \$ 89,94$ e $R \$$ 65,99 , respectivamente. Quando se comparam esses valores com os apresentados na Tabela 2, fica evidente o nível de desigualdade na sociedade paranaense. Em 2015 , por exemplo, o rendimento domiciliar médio no estado era de $\mathrm{R} \$ 1.442,87$, mais de 21 vezes o rendimento nos domicílios classificados como pobres.

No início do período, entre os domicílios pobres, o percentual de chefes homens era maior do que o de chefes mulheres, $88 \%$ e $12 \%$, respectivamente. Ao final do período, observou-se aumento significativo no percentual de chefes mulheres, que alcança metade dos domicílios pobres. Seguindo esse comportamento, a proporção do rendimento dos domicílios chefiados por homens também sofre redução, de $88 \%$ para $46 \%$. Em relação ao rendimento domiciliar médio, os domicílios chefiados por homens apresentavam maior rendimento em 1995, mas, em 2015, o maior rendimento passou a ser notado nos domicílios chefiados pelas mulheres. Esses resultados indicam que, em termos relativos, 
aumentou significativamente a proporção de domicílios chefiados por mulheres entre os domicílios pobres.

Em 1995, entre os domicílios pobres, a proporção daqueles chefiados por brancos era maior do que a proporção chefiada por não brancos, 61\% e 39\%, respectivamente. Todavia, no período, ocorreu redução na proporção de chefes brancos e elevação na proporção de chefes não brancos, sendo que, no final do período, a proporção destes atingiu 46\%. Seguindo esse perfil, a proporção do rendimento entre os domicílios chefiados por não brancos é menor do que entre os chefiados por brancos no início do período, mas, em 2015, igualam-se. Já o rendimento domiciliar per capita dos domicílios pobres com chefes não brancos, no início do período, era inferior ao daqueles cujos chefes eram brancos, porém, em 2015, passa a ser maior.

Tabela 4 - Proporção dos domicílios e dos rendimentos, e o rendimento domiciliar per capita médio em subgrupos da população pobre - Paraná (1995-2015)

\begin{tabular}{|c|c|c|c|c|c|c|c|c|c|}
\hline \multirow{2}{*}{ Variável } & \multicolumn{3}{|c|}{$\begin{array}{l}\text { Proporção de } \\
\text { domicílios }\end{array}$} & \multicolumn{3}{|c|}{$\begin{array}{l}\text { Proporção do } \\
\text { rendimento }\end{array}$} & \multicolumn{3}{|c|}{$\begin{array}{l}\text { Rendimento domiciliar } \\
\text { per capita médio }\end{array}$} \\
\hline & 1995 & 2005 & 2015 & 1995 & 2005 & 2015 & 1995 & 2005 & 2015 \\
\hline Paraná & 100 & 100 & 100 & 100 & 100 & 100 & 93,59 & 89,94 & 65,99 \\
\hline \multicolumn{10}{|l|}{ Sexo } \\
\hline Homens & 0,12 & 0,21 & 0,50 & 0,12 & 0,21 & 0,56 & 97,50 & 90,06 & 73,78 \\
\hline Mulheres & 0,88 & 0,79 & 0,50 & 0,88 & 0,79 & 0,44 & 102,23 & 89,91 & 58,80 \\
\hline \multicolumn{10}{|l|}{ Cor } \\
\hline Não branco & 0,39 & 0,40 & 0,46 & 0,38 & 0,40 & 0,50 & 98,66 & 90,29 & 71,82 \\
\hline Branco & 0,61 & 0,60 & 0,54 & 0,62 & 0,60 & 0,50 & 103,56 & 89,70 & 61,07 \\
\hline \multicolumn{10}{|l|}{ Educação } \\
\hline Menor de 1 ano & 0,32 & 0,15 & 0,17 & 0,31 & 0,16 & 0,19 & 98,67 & 94,97 & 76,61 \\
\hline 1 até 3 anos & 0,31 & 0,27 & 0,10 & 0,31 & 0,25 & 0,10 & 102,32 & 84,28 & 61,73 \\
\hline 4 até 7 anos & 0,30 & 0,38 & 0,33 & 0,31 & 0,41 & 0,37 & 104,28 & 95,72 & 74,72 \\
\hline 8 até 10 anos & 0,05 & 0,12 & 0,21 & 0,05 & 0,13 & 0,19 & 102,12 & 93,40 & 59,45 \\
\hline 11 até 14 anos & 0,02 & 0,07 & 0,17 & 0,02 & 0,05 & 0,15 & 97,04 & 63,51 & 60,18 \\
\hline 15 anos ou mais & 0,00 & 0,00 & 0,03 & 0,00 & 0,00 & 0,00 & 0,00 & 85,70 & 0,00 \\
\hline \multicolumn{10}{|l|}{ Idade } \\
\hline Até 24 anos & 0,06 & 0,07 & 0,10 & 0,06 & 0,08 & 0,09 & 104,42 & 103,55 & 58,10 \\
\hline 25-34 anos & 0,30 & 0,26 & 0,24 & 0,31 & 0,26 & 0,25 & 104,68 & 87,94 & 66,70 \\
\hline $35-49$ anos & 0,41 & 0,44 & 0,37 & 0,40 & 0,44 & 0,39 & 98,45 & 88,53 & 69,30 \\
\hline 50-64 anos & 0,19 & 0,19 & 0,26 & 0,19 & 0,18 & 0,25 & 101,92 & 88,64 & 63,25 \\
\hline 65 ou mais & 0,04 & 0,04 & 0,02 & 0,04 & 0,04 & 0,02 & 106,44 & 102,60 & 71,18 \\
\hline \multicolumn{10}{|l|}{ Região } \\
\hline Não-Metropolitana & 0,92 & 0,80 & 0,80 & 0,92 & 0,82 & 0,83 & 101,32 & 92,14 & 68,63 \\
\hline Metropolitana & 0,08 & 0,20 & 0,20 & 0,08 & 0,18 & 0,17 & 105,54 & 80,92 & 55,64 \\
\hline \multicolumn{10}{|l|}{ Domicílio } \\
\hline Rural & 0,48 & 0,29 & 0,24 & 0,47 & 0,32 & 0,32 & 99,24 & 97,81 & 87,17 \\
\hline Urbano & 0,52 & 0,71 & 0,76 & 0,53 & 0,68 & 0,68 & 103,87 & 86,71 & 59,16 \\
\hline
\end{tabular}

Fonte: Elaboração própria a partir das informações básicas das PNADs. 
Quanto ao nível educacional, em 1995, mais de a metade dos domicílios pobres tem chefes com no máximo 3 anos de estudo. Além disso, cerca de $90 \%$ são domicílios cujos chefes têm até 7 anos de estudo. No entanto, ao longo do tempo, verificou-se redução na proporção de domicílios cujos chefes têm menor escolaridade, para $60 \%$ com até 7 anos, e, por sua vez, elevação na proporção daqueles com mais anos de estudo. Ademais, os maiores rendimentos médios encontram-se em domicílios cujos chefes tem até 7 anos de estudos. Desse modo, pode ser observado que o nível educacional do chefe não se refletiu em rendimentos, o que pode ser explicado pela baixa proporção de chefes nesses níveis de escolaridade ou, talvez, pelo fato de domicílios com chefes de maior nível de escolaridade classificados em situação de pobreza estejam nessa condição devido a alguma característica não captada em dados das PNADs.

Refletindo o envelhecimento da população brasileira, $41 \%$ dos domicílios pobres, no início do período, tinham chefes com idade de 35 até 49 anos, mas, em 2015 , o percentual nessa faixa caiu para pouco mais de $37 \%$, enquanto a proporção da população pobre acima dos 50 anos ascendeu de $23 \%$ para 28\%. Tanto em 1995 quanto em 2015, o maior rendimento médio domiciliar estava naqueles domicílios cujo chefe tinha idade na faixa de 65 ou mais anos, além disso, em 2005, essa faixa tinha o segundo maior rendimento. Esses resultados podem indicar que os rendimentos de aposentadorias e pensões contribuem para majorar a renda dos domicílios pobres.

Em 1995, a Região Metropolitana de Curitiba detinha apenas 8\% dos domicílios pobres do estado. No entanto, em 2015, tal percentual subiu para $20 \%$. A mesma tendência ocorreu com a proporção do rendimento domiciliar, que aumentou para a Região Metropolitana. Em relação ao rendimento domiciliar médio, nota-se que nas regiões não metropolitanas esse rendimento passou a ser superior. Desse modo, a pobreza parece ter se intensificado mais na Região Metropolitana de Curitiba. Carece, porém, saber se isso se deve a uma migração dos mais pobres para essa região ou se é devido a um maior acréscimo relativo endógeno desses domicílios em função de maior taxa de natalidade dos mais pobres nessa região.

Apesar de os domicílios rurais representarem apenas $16 \%$ do total de domicílios no Paraná em 1995, eles detinham 48\% dos domicílios classificados como pobres. Com a maior urbanização no período, refletida na queda para $12 \%$ 
da participação de residências no meio rural, a proporção da pobreza nesse meio também caiu para 24\%, em 2015. Portanto a atenuação da pobreza nessa região foi mais intensa que a diminuição dos domicílios rurais, indicando que o decréscimo de lares pobres foi relativamente maior no campo.

Os resultados deste trabalho apontam contração da pobreza e da extrema pobreza no Paraná nas duas décadas que se sucederam a 1995. Enquanto a situação de pobreza caiu de $12,8 \%$ para 2,4\% dos domicílios nesses dois decênios, a de extrema pobreza foi de 4,2\% para 1,4\%. Porém essa trajetória de encolhimento da pobreza e da extrema pobreza parece ter sido interrompida ao final do período, de 2014 para 2015, como um reflexo da crise econômica e política do país. O perfil dos domicílios pobres se modificou no período, pois acresceu a proporção de domicílios chefiados por mulheres, não brancos, mais escolarizados, mais velhos, residentes na Região Metropolitana de Curitiba e nos centros urbanos.

Assim, os diversos indicadores aqui apresentados permitem inferir que a saída da pobreza foi maior para alguns grupos da população, como para os chefes homens e brancos, sugerindo que a vulnerabilidade da população feminina e não branca mostra-se superior. Verificou-se que a ascensão do nível de escolaridade e o envelhecimento da população brasileira também se refletiram no perfil dos domicílios pobres. Além disso, há evidências de que as cidades e, em especial, a região metropolitana de Curitiba não têm conseguido absorver adequadamente o seu crescimento populacional, pois vem ocorrendo aumento relativo da pobreza nessas áreas.

\section{Considerações finais}

Neste trabalho, foi apresentada e discutida a evolução da desigualdade na distribuição da renda e da pobreza no estado do Paraná de 1995 até 2015. Observou-se queda tanto na desigualdade da distribuição de renda quanto na pobreza e na extrema pobreza, especialmente na primeira década do século XXI. No entanto, esse processo foi interrompido pela crise econômica e política do final do período, que se refletiu, na análise de 2014 para 2015, com aumentos da desigualdade e da pobreza.

A partir dos resultados aqui expostos, o estado do Paraná, conforme critérios estabelecidos na literatura sobre o tema e apesar dos avanços observados no período de 1995 a 2015, ainda pode ser considerado composto por uma 
sociedade extremamente desigual, com um índice de Gini de 0,473 e com uma renda apropriada pelos domicílios $10 \%$ mais ricos, os $40 \%$ seguintes e os $50 \%$ mais pobres, respectivamente, igual a 38\%, 42\% e $20 \%$ em 2015.

Afinal, em 2015, seu índice de Gini permaneceu acima de 0,450 e a renda domiciliar apropriada pelos $10 \%$ mais ricos correspondeu a $38 \%$ da renda total, enquanto os $50 \%$ mais pobres ficaram com apenas $20 \%$. Esses indicadores apontam a necessidade de amplos avanços econômicos e sociais para o Paraná efetivamente se tornar comparável com sociedades observadas em países de renda média, tais como Polônia, Chile ou Estônia.

Destaca-se a contribuição dos diferenciais de escolaridade para a explicação da desigualdade na distribuição da renda no estado. A despeito de perder peso relativo ao longo do período analisado entre as variáveis explicitadas no estudo, o nível de escolaridade do chefe de domicílio ainda se mostrou como o determinante mais relevante.

Com relação à pobreza, foi possível observar que, apesar da sua redução no período avaliado, ganharam participação relativa os domicílios chefiados por mulheres e não brancos, além de localizados na Região Metropolitana de Curitiba e em áreas urbanas. Nesse sentido, os resultados do presente trabalho apontam para a necessidade de ampliação de políticas públicas mais focalizadas nesses grupos, que parecem ser os mais vulneráveis da população paranaense.

\section{Referências}

ALBUQUERQUE, M. R.; SILVA, M. S. Uma análise de pobreza sob o enfoque multidimensional no Paraná. Revista de Economia, v. 38, n. 3, p. 45-64, 2012.

ATKINSON, A. B. Desigualdade: o que pode ser feito? São Paulo: LeYa, 2015.

ARAUJO, J. R.; SALVATO, M. A.; SOUZA, P. F. L. Decomposição do índice de Theil-T em disparidades regionais entre gêneros, raciais e educacionais: uma análise da desigualdade da renda na região Sul. Anais do XI Encontro de Economia da Região Sul (ANPEC-SUL), 2008.

BAER, W. A economia brasileira. São Paulo: Nobel, 2009.

BARROS, R. P.; MENDONÇA, R. S. P.; DUARTE, R. P. N. Bem-estar, pobreza e desigualdade de renda: uma avaliação da evolução histórica e das disparidades regionais. Texto para discussão IPEA, n. 454, 1997. 
BASTOS, E. K. X. Distribuição funcional da renda no Brasil: estimativas anuais e construção de uma série trimestral. Texto para discussão IPEA, n. 1702, 2012.

CANCIAN, V.; VIDIGAL, V. G.; VIDIGAL, C. B. R. Pobreza e desigualdade de renda nos municípios da Região sul do Brasil: uma análise espacial. Anais do XVI Encontro de Economia da Região Sul (ANPEC-SUL), Curitiba, PR, 2013.

CORSEUIL, C. H.; FOGUEL, M. N. Uma sugestão de deflatores para rendas obtidas a partir de algumas pesquisas domiciliares do IBGE. Texto para Discussão IPEA, n. 897, jul. 2002.

COUTO, A. C. L.; BRITO, E. C.; COUTO J. M. Evolução da pobreza no Paraná (2003-2013). Gestão e Desenvolvimento em Revista, v. 1, n. 2, 2015.

CUNHA, M. S.; VASCONCELOS, M. R, Diferenciais de salários intersetoriais no mercado de trabalho paranaense. Revista de Economia, v. 37, n. 7, p. 31-52, 2011.

FERREIRA, C. R.; SOUZA, S. C. O comportamento da desigualdade da renda no Paraná de 2001 a 2005: uma análise do rendimento domiciliar per capita. Revista Paranaense de Desenvolvimento, n.112, p.31-45, 2007.

FERREIRA, C. R.; SOUZA, S. C. A contribuição da parcela do rendimento domiciliar per capita 'aposentadorias e pensões' para a desigualdade da renda no Brasil, Região Sul e Estado do Paraná. Revista Paranaense de Desenvolvimento, n. 106, p. 29-48, 2004.

FURTADO, C. Formação Econômica do Brasil. São Paulo: Nacional, 1989.

GREMAUD, A. P.; VASCONCELOS, M. A. S.; TONETO JÚNIOR, R. Economia Brasileira Contemporânea. São Paulo: Atlas, 2012.

GOMES, C. E.; LIMA, R. L.; CUNHA, M. S.; VASCONCELOS, M. R. Transições no mercado de trabalho brasileiro e os efeitos imediatos da crise econômica recente. Economia e Sociedade, v. 28, n. 2 (66), p. 481-511, 2019.

HOFFMANN, R. Distribuição de renda: medidas de desigualdade e pobreza. São Paulo: Editora da Universidade de São Paulo, 1998.

HOFFMANN, R. Transferência de renda e a redução da desigualdade no Brasil e cinco regiões entre 1997 e 2004. Econômica, v. 8, n. 1, p. 55-81, 2006.

HOFFMANN, R. Medidas de polarização da distribuição da renda e sua evolução no Brasil de 1995 a 2013. Economia e Sociedade, v. 26, n. 1 (59), p. 165-187, 2017. 
HOFFMANN, R. A desigualdade relevante não caiu de 2014 a 2015. 16p, 2016. Disponível em: http://iepecdg.com.br/wp-content/uploads/2016/12/RH2015B.pdf.

LERMAN, R. I.; YITZHAKI, S. Income inequality effects by income source: A new approach and applications to the United States. Review of Economics and Statistics, v. 67, 151-156, 1985.

LOVELL, P. A. Development and the Persistence of Racial Inequality in Brazil: 1950-1991. The Journal of Developing Areas, v. 33, n.3, 395-418, 1999.

LUEBKER, M. Inequality, income shares and poverty: The practical meaning of Gini coefficients. Travail Policy Brief, Genebra, n. 3, 2010.

MUNHOZ, J. P. Indicadores de pobreza: limites e potenciais na mensuração da pobreza no Paraná. Mestrado em Desenvolvimento Econômico. Universidade Federal do Paraná, 2009.

NEDER, H. D.; SILVA, J. L. M; Pobreza e distribuição de renda em áreas rurais: uma abordagem de inferência. Anais do XXXI Encontro Nacional de Economia. Porto Seguro, 2003.

NÓBREGA, W. Mapeamentos da pobreza sob critérios unidimensional e multidimensional para os estados do Paraná e Sergipe. Doutorado em Desenvolvimento Econômico. Universidade Federal do Paraná, 2008.

OECD - Organization for Economic Co-operation and Development. OECD income distribution database (idd): gini, poverty, income, methods and concepts. Disponível em: http://www.oecd.org/social/income-distribution-database.htm. Acesso em: set. 2017.

PIKETTY, T. Capital in the twenty-first century. The Belnap Press of Harvard University Press. 2014.

ROCHA, S. Pobreza no Brasil: afinal, de que se trata? Rio de Janeiro: Ed. da FGV, 2003.

ROLIM, C.; ANDRADE, J. R. L.; SANTANA, J. R.; MELO, R. O. L. Construção de indicadores de pobreza: aplicação do índice de pobreza humana municipal no estado de Sergipe. Revista Econômica do Nordeste, v. 37, n. 4, p. 512-529, 2006.

SILVA, L. N. S.; BORGES, M. J.; PARRÉ, J. L. Distribuição Espacial da Pobreza no Paraná. Revista de Economia, v. 39, n. 3 (ano 37), p. 35-58, 2013. 
SOUZA, S. C. I.; BESSA, D. C.; MARGONATO, R. C. G.; FERREIRA, C. R. Rendimento do trabalho, posições na ocupação e desigualdade da renda no Paraná. Ensaios FEE, v. 37, n. 4, p. 925-946, 2017.

SOUZA, S. C. I.; FERREIRA, C. R. Rendimentos do trabalho e de outras rendas e a queda da concentração de renda no Paraná. Economia e Tecnologia, Curitiba, v. 8, n. 2, p. 81-90, 2012.

UNU-WIDER World. Income Inequality Database. Disponível em: http://www.wider.unu.edu/research/Database/en_GB/database/. Acesso em: set. 2017. 